\title{
Determinações históricas e epistemológicas mediante relações contraditórias dos PNPG
}

Kátia Oliver de Sá
Pesquisadora dos grupos Lepel (UFBA) e Paideia (Unicamp)
Moisés Henrique Alves
Professor de Educação Física e membro do grupo Lepel (UFBA)
Ivson Conceição Silva
Mestrando em Educação e membro do grupo Lepel (UFBA)

\section{Resumo}

Este trabalho identifica a realidade da produção do conhecimento stricto sensu em Educação Física de professores que trabalham em cursos de formação no estado da Bahia - 1982 a 2012 -, em vista as determinações históricas e epistemológicas. É parte da pesquisa em rede EPISTEFNORDESTE. Fonte de dados/informações: 142 produções stricto sensu e 5 PNPG. A metodologia tem base dialética. Resultados apontam que os PNPG, alicerçados na lógica do modo de produção capitalista, geram produções que encerram limites lógicos que são entraves para o avanço da área de Educação Física na construção de uma consistente base teórica que responda aos reais problemas que a área vem impondo historicamente.

Palavras-chave: Produção do conhecimento; Epistemologia; Educação Física.

\begin{abstract}
This paper identifies the reality of the production of knowledge stricto sensu in Physical Education teachers working in training courses in the state of Bahia 1982 to 2012 - in view of the historical and epistemological determinations. It is part of the research network EPISTEFNORDESTE. Source of data / information: 142 productions strictly and PNPG 5. A dialectical methodology is based. Results show that the PNPG, grounded in the logic of the capitalist mode of production, generate productions that contain logical boundaries that are barriers to the advancement of the field in the construction of a consistent theoretical basis responsive to the real problems that the area historically has imposed.
\end{abstract}

Keywords: Production of knowledge: Epistemology; Physical Education. 


\section{Introdução}

$\mathrm{E}$

ste artigo sistematiza parte dos resultados de uma pesquisa em rede denominada de EPISTEFNORDESTE ${ }^{1}$ que vem sendo desenvolvida pelo grupo LEPEL/FACED/UFBA em articulação com o grupo PAIDEIA/FE/UNICAMP. Essa pesquisa matricial tem por objetivo o reconhecimento do impacto do sistema de pós-graduação das regiões sul e sudeste do Brasil na formação e produção de mestres e doutores que atuam nas instituições de ensino superior da região nordeste.

A necessidade e relevância desta investigação ocorreram pelo fato de que as universidades brasileiras no atual processo de oferta para a formação da graduação e pós-graduação vêm se afirmando em uma política de expansão de oferta que se sustenta, dentre outros fatores pela flexibilidade, competitividade e avaliação. Essa determinação advém da política de ajustamento do sistema ao crescimento da demanda e ao atendimento das exigências impostas pelo mercado alimentado pelo capital planetário que tem domínio sobre todas as dimensões da produção da vida humana.

Esse processo é condicionado e de certa maneira determinado em grande parte das instituições pelas atuais políticas de educação superior, que procuram estabelecer competição para abarcar financiamentos para ampliar índices de produtividade na pesquisa da pós-graduação, a partir de mecanismos de avaliação e controle do trabalho acadêmico.

Há uma crescente oferta de cursos de graduação e pós-graduação, apesar da diminuição crescente de professores e servidores técnicoadministrativos nas Instituições de Ensino Superior (IES). Associada a esse fator, o trabalho acadêmico, tanto da graduação como na pós-graduação vêm se tornando alheio à rigorosidade que exige a produção científica para responder ao exercício crítico da realidade. A própria Coordenação de Aperfeiçoamento Pessoal de Nível Superior (CAPES), enquanto um organismo do governo, em sua avaliação a cada triênio, contraditoriamente,

\footnotetext{
${ }^{1}$ Os relatórios e planilhas dessa pesquisa que vêm sendo produzidos pelo coletivo do LEPEL/FACED/UFBA e PAIDÉIA/FE/UNICAMP, cuja investigação encontra-se em execução e será concluída no ano de 2015, estão disponíveis em um serviço de armazenamento online denominado de DROPBOX. Para o acesso aos arquivos, usar o email: epistefdropbox@gmail.com e a senha epistefdropbox2014.
} 
reconhece que a objetivação da evolução do produtivismo e o pragmatismo a que a ele está associado no meio acadêmico, são fatores que vêm alimentando a produção intelectual de professores da pós-graduação (SILVA JÚNIOR; FERREIRA; KATO, 2013, p. 444).

Diante das condições objetivas que estão colocadas, problematizar a produção do conhecimento desenvolvida na região nordeste do Brasil é de extrema relevância. Nesse sentido, propomos na sistematização desse trabalho apresentar a partir da análise da produção do conhecimento stricto sensu dos professores de Educação Física que trabalham nos cursos de formação de professores de Educação Física das IES do estado da Bahia, considerando o período de 1982 a 2012, elementos das determinações epistemológicas e históricas que alicerçam essa produção, apontando as contradições que são evidenciadas em vista as relações que apontam os Planos Nacionais de Programas de Pós-Graduação (PNPG) no Brasil.

No que diz respeito às determinações epistemológicas, buscamos investigar em 67 produções stricto sensu levantadas a partir da identificação de (142) produções no estado da Bahia, as bases das lógicas (formal e dialética), que os professores de Educação Física desenvolveram na produção de suas pesquisas, procurando apontar os seus limites e possibilidades $^{2}$. No que diz respeito às determinações históricas, foram identificadas as influências da política de pós-graduação no Brasil através de uma breve análise dos PNPG existentes.

Para responder a essa problemática investigativa, partimos do método do materialismo histórico dialético, em vista ao movimento do pensamento que garante a conquista de resultados objetivos verdadeiros, que refletem com precisão no pensamento, as leis do desenvolvimento da realidade estudada, garantindo o conteúdo objetivo do conhecimento tratado na investigação. Nesse sentido, trabalhar com as leis e categorias da dialética materialista, enquanto método do movimento do pensamento nos permitiu obter novos resultados; essas leis constituem a base em que alicerçamos os

${ }^{2}$ O processo de análise epistemológica das (67) produções ocorreu a partir de 21 campos (formais e epistemológicos). Nesse estudo, enquanto recorte empírico da pesquisa estão sendo referenciados somente dois campos epistemológicos de análise: Teorias utilizadas ou elaboradas e concepção de homem/sociedade. 
momentos da investigação da pesquisa, considerando nossas ações para domínio da realidade que apontam as produções analisadas.

O procedimento do levantamento de fontes de dados e o processo metodológico da investigação, assim como a análise, se desenvolveram em três graus de desenvolvimento do pensamento investigativo com vistas à apropriação do objeto da investigação, segundo as bases indicadas por Kosik (1995, p. 37): 1. Minuciosa apropriação histórica do objeto com pleno domínio do material investigado. Nesse processo se encontram incluídos, dados históricos aplicáveis e disponíveis (esse processo se desenvolveu desde o momento inicial exploratório da investigação). 2. Análise das formas de desenvolvimento do material investigativo sobre o objeto. Esse processo de sistematização e organização de informações e dados, para atender ao processo de análise, ocorreu em quatro momentos: a) Identificação de (142) produções stricto sensu para levantamento de dados epistemológicos de (67) produções para compor planilhas/quadros que correspondem aos bancos de dados das fontes da pesquisa. b) Elaboração do substrato material objetivo e concreto dos traços da realidade objetiva ${ }^{3}$, considerando a sistematização de dados dos campos em planilhas que agruparam elementos extraídos das 67 produções stricto sensu. c) Nesse momento foram trabalhados procedimentos de análise e discussão dos elementos epistemológicos tratados sobre o objeto; sínteses foram elaboradas para responder a pergunta investigativa e atender aos objetivos da investigação proposta; 3 . Investigação da coerência interna do objeto. Com esse grau de desenvolvimento do pensamento foi possível elaborar essa síntese que expomos enquanto artigo científico.

\section{Relações de base sustentadas na produção do conhecimento na formação econômica capitalista}

Para que possamos compreender o movimento da produção do conhecimento em Educação Física, esporte e lazer no estado da Bahia em

\footnotetext{
${ }^{3}$ Na tese de Sá (2009, f. 61), em que é desenvolvida análise epistemológica do resumo de teses e dissertações de estudos do lazer no Brasil, é definido o substrato material e concreto dos traços da realidade objetiva, como sendo a síntese que permite obter elementos das produções stricto sensu, cuja "lógica significa o meio através do qual o pensamento realiza a tarefa de apropriar-se do real em toda a sua objetividade".
} 
vistas a um recorte histórico, temos que considerá-lo em suas relações contraditórias com o modo de produção no qual está inserida, pois entendemos que somente dessa maneira é que poderemos reproduzir na consciência, através do conhecimento sistematizado, o reflexo concreto do que apresenta o balanço dessa produção. Nessa síntese, buscamos os nexos da produção do conhecimento, mediante a formação econômica capitalista, considerando as bases de sua sustentação porque é preciso dominar suas múltiplas relações que advém de determinações materiais para desenvolver o processo final de análise.

Essa base a que nos referimos é a própria produção da existência dos seres humanos que implica em reconhecer como estes produzem a história, como nos afirma Marx e Engels (2005, p. 53):

[...] o primeiro pressuposto de toda a existência humana e, portanto, de toda a história, é que todos os homens devem estar em condições de viver para fazer história. Mas para viver é preciso antes de tudo comer, beber, ter moradia, vestir-se e algumas coisas mais. O primeiro fato histórico é, portanto, a produção dos meios que permitam que haja a satisfação destas necessidades, a produção da própria vida material, e de fato esse é um ato histórico uma exigência fundamental de toda a história, que tanto hoje como há milênios deve ser cumprido cotidianamente e a toda hora, para manter os homens com vida.

A produção da vida, isto é, dos bens materiais necessários à sobrevivência do homem é o aspecto decisivo, é à base do desenvolvimento social. Por isso é impossível compreender a vida da sociedade fora de seu intercâmbio com a natureza, pois a sua origem e a do próprio homem está ligada a ela.

Portanto, o conhecimento não pode ser compreendido como um fenômeno autônomo, como algo que está além das determinações da materialidade da vida, isto é, das condições materiais da produção que determinam profundamente os interesses dos pesquisadores; em cada período diferente do desenvolvimento histórico da sociedade se estabelecem determinadas concepções de realidade, que são formas de conceber os 
fenômenos sociais e naturais que estão indissoluvelmente ligadas às condições materiais de vida dos seres humanos.

Foi essa a conclusão que Marx chegou em seus estudos e que nos serviu também de fio condutor em nossa investigação:

[...] Na produção social da própria existência, os homens entram em relações determinadas, necessárias, independentes de sua vontade; estas relações de produção correspondem a um grau determinado de desenvolvimento de suas forças produtivas materiais. A totalidade dessas relações de produção constitui a estrutura econômica da sociedade, a base real sobre a qual se eleva uma superestrutura jurídica e política e à qual correspondem formas sociais determinadas de consciência. O modo de produção da vida material condiciona o processo de vida social, política e intelectual. Não é a consciência dos homens que determina o seu ser, ao contrário, é o seu ser social que determina a sua consciência (KARL MARX, 1980, p. 301- 302).

Considerando que a história da sociedade caracteriza-se, segundo Marx e Engels (2008 p. 8), pela história de lutas de classes, da luta entre opressores e oprimidos, desde a dissolução da sociedade primitiva, o conhecimento produzido pela humanidade configura-se a partir de interesses humanos, que podem variar segundo a posição de classe assumida por quem o produz.

No modo de produção capitalista isto não é diferente; nesta formação social, a luta entre a classe burguesa e a classe operária pelo poder político determina, inevitavelmente, a produção do conhecimento, o que acaba por gerar diferentes métodos de movimento do pensamento e interesses na busca do conhecimento que atenda a posição de classes que o pesquisador defende na produção da vida.

É isso que explica, portanto, as contradições no que se refere às funções que a ciência tem assumido na sociedade, como nos afirma Kopnin (1972, p. 5): 
[...] por força da contradição do desenvolvimento da sociedade em que existe antagonismo de classe, os resultados da ciência são aplicados não somente em beneficio do homem; são aplicados também, para o seu mal. A ciência e a técnica que surgem em sua base podem tornar-se (e se tornam) uma força hostil ao homem. Hoje é comum ouvirem-se alusões às forças demoníacas da ciência, de cujos resultados o próprio homem se torna escravo.

Por isso, a ciência não pode ser compreendida por si mesma, como algo autônomo e separado da luta de classes $^{4}$ da qual faz parte e na qual adquiri sua concretude. A produção do conhecimento se introduz na cadeia de relações complexas da totalidade social e, enquanto elemento da superestrutura social, esta é determinada em última instância pelas condições de existência no modo de produção capitalista.

Partimos do pressuposto que vivemos em uma sociedade dividida em duas grandes classes com interesses antagônicos: a burguesia, detentora dos meios de produção (terra, matéria prima, instrumentos, domínio de conhecimentos e da maneira de produzi-la) e o proletariado, classe que só possui sua força de trabalho e que é obrigada a vendê-la ao burguês se quiser sobreviver.

Aos burgueses interessa que as relações de produção assentadas na propriedade privada dos meios de produção, na exploração do trabalho assalariado e na extração da mais-valia, que configura a ordem sociometabólica atualmente vigente, seja conservada, pois daí resulta as bases das condições para erigir e manter imensos privilégios sociais e econômicos. E para isso é lançado mão de diversos meios de propagação da ideologia neoliberal (escola, cinema, mídia televisiva e impressa) como sendo universal, isto é, o melhor para todos.

\footnotetext{
${ }^{4}$ Tomamos a categoria "luta de classes" a partir de Marx (s/d, p. 253-254): Carta de Weydemeyer, 8 de março de 1985. Nessa carta Marx ressalta que não lhe cabe o mérito de haver descoberto nem a existência das classes, nem a luta entre elas. $O$ que destaca de novo em seus estudos é a necessidade: "1. demonstrar que a existência das classes está ligada somente às determinadas fases de desenvolvimento da produção; 2 . que a luta de classes conduz, necessariamente, à ditadura do proletariado; 3 . que essa própria ditadura nada mais é do que a transição à abolição de todas as classes e a uma sociedade sem classes. [...]" (grifo do autor).
} 
O domínio da produção material resulta para esta classe, também, o poder privilegiado sobre os meios de produção de ideias, da propagação de concepção de mundo através da qual exercem o seu domínio também no plano ideal, pois como nos afirmam Marx e Engels (2005, p. 78) "as ideias dominantes são, pois, nada mais que a expressão ideal das relações materiais dominantes, são essas as relações materiais dominantes compreendidas sob a forma de ideias". Isto nos faz reconhecer que há um domínio do conhecimento produzido, enquanto instrumento de poder da classe dominante sobre a classe dominada.

Muitas das produções stricto sensu elaboradas na pós-graduação de universidades no Brasil e mais especificamente na região nordeste têm sido, desde sua emergência histórica ${ }^{5}$ uma dessas formas de propagação das ideias de dominação da classe burguesa que se expressam em produções científicas, cujas concepções de mundo idealistas, negam ou relativizam a realidade concreta e que, portanto, negam a possibilidade da transformação social.

À classe proletária interessa não mais do que a dissolução de todo o estado de coisas da ordem vigente; sua condição de vida pauperizada e miserável é cada vez mais agravada pela realidade da lógica de criação destrutiva do capital que é sua própria condição de existência enquanto classe revolucionária. Ao refletir a realidade do processo de desenvolvimento histórico da produção do conhecimento, analisando as relações de sua base real, identificamos que esta não interessa ao proletariado, pois contraria seus interesses.

Podemos constatar, portanto, que o conhecimento científico que é produzido no interior da sociedade capitalista tem caráter de classe; isto significa dizer que não há o conhecimento científico não é neutro, implica determinadas posições políticas e ideológicas; ele se move nas contradições entre concepções idealistas e materialistas, entre os métodos metafísico e dialético desenvolvidos nas produções de pesquisa.

\footnotetext{
${ }^{5}$ A primeira produção stricto sensu no campo da Educação Física na Região Nordeste foi de mestrado, produzida em 1982 por Fonte: Planilha II-D dessa pesquisa (código BA096).
} 
Mediante o exposto, reconhecemos nessa pesquisa, que as relações de base que alimentam as contradições fundamentais que constituem a formação econômica capitalista, vêm determinando de uma forma geral a produção do conhecimento científico desenvolvida nos programas de pósgraduação.

\section{Contradições da produção do conhecimento geradas por condições objetivas da crise estrutural do capital}

O modo de produção capitalista caracteriza-se por uma fase específica do desenvolvimento histórico da humanidade no processo de produção da sua existência, que surgiu das ruínas da sociedade feudal e cuja base essencial se expressa na relação contraditória entre capital e trabalho e entre as forças produtivas e relações de produção. Essas contradições se dão não pela existência de conflitos individuais, nem por conta de uma pretensa natureza mesquinha e egoísta entre homens que vivem em sociedade em condições objetivas diferentes, mas decorrem da própria lógica de organização da vida do capital que subsume tudo, o trabalho, as necessidades humanas, a natureza, a produção do conhecimento e tudo o mais, por interesse de ampliação do lucro.

Ainda, para Engels (s/d, p. 58-60) esses conflitos consistem na contradição existente entre a produção social e a apropriação capitalista dos bens materiais e imateriais ${ }^{6}$ e que, por sua vez se revestem na essência em processos contraditórios de interesses entre o proletariado e a burguesia.

A produção capitalista dos bens materiais e imateriais caracteriza-se pela forma mais desenvolvida de produção social, uma vez que esta estabelece divisão e planejamento complexo do trabalho de forma que não é

\footnotetext{
${ }^{6}$ Segundo Taffarel (2010, p. 22): “Entre os produtos que o trabalho do homem é capaz de gerar, existem aqueles que são produtos materiais, que se integram à lógica do valor de troca e se transformam em mercadoria nas relações sociais capitalistas. Mas existem também os produtos não-materiais que não se conformam facilmente à lógica capitalista de valor de troca. Encontramos aí os produtos que são consumidos no ato da produção, como a produção de uma aula de um professor. A aula é um tipo de produto não material, que se consome no ato de produção, e que apesar das resistências está sujeito ao processo de mercantilização, sofrendo alterações em suas qualidades mais íntimas".
} 
possível conceber um produto da produção coletiva ${ }^{7}$. De certa maneira, ainda podemos encontra a produção individual de produtos nos dias de hoje, na forma de produção desenvolvida nos moldes da sociedade feudal, mas em condições rudimentares, em relações societárias do campo.

Mas, apesar do capitalismo ter revolucionado o modo de produção predominantemente individual da sociedade feudal, manteve em seu conteúdo sob outra forma, a apropriação privada dos produtos e meios de produção; foi nesse interesse que consistiu o papel histórico da burguesia: Concentração dos meios de produção.

Portanto, todas as contradições específicas inerentes à formação econômica capitalista se revestem em geral na contradição entre interesses da classe trabalhadora e da classe burguesa.

Mediante o exposto, apontamos que as contradições da formação econômica capitalista e as contradições da produção do conhecimento são provenientes de uma mesma base. Os meios de produção do trabalho da produção do conhecimento que advém dos instrumentos de pesquisa, também servem para medir o desenvolvimento da força humana de trabalho e indicam as condições sociais que se realiza e a que interesses atendem.

Portanto, a natureza contraditória do capital engendra todas as possibilidades humanas de produção, e na produção teórica encontra um grande lastro para fortalecer indicadores de que não há contradições e luta de classes.

As pesquisas que alimentam os interesses das bases do capitalismo alicerçam-se em uma realidade que ignora os problemas diários que a humanidade enfrenta na luta pela vida, alimentando-se, portanto, na especulação absoluta que nega dados da ciência que fundamenta uma dada lógica material.

Desde o início de século XX, o modo de produção capitalista vem passando por muitas transformações provenientes do desenvolvimento do agravamento de suas próprias contradições. Da produção e exportação de

\footnotetext{
${ }^{7}$ Em contraposição a existência do trabalho socialmente útil, Frigotto (1984, p. 78) ressalta a existência nas relações de produção econômica capitalista do trabalho, enquanto "força de trabalho", cujo processo visa criar atividades dirigidas com o fim de criar valores de uso, pois é trabalho genérico, abstrato, um trabalho separado dos sujeitos.
} 
mercadorias e livre concorrência, passamos para a fase de predomínio da especulação financeira, exportação de capitais e dominação de monopólios ${ }^{8}$.

O surgimento do imperialismo agrava, ainda mais as contradições entre as forças produtivas e as relações de produção porque a produção mantém-se, contraditoriamente com caráter de formação social, na medida em que a produção é baseada nos monopólios, mas promovendo uma maior concentração da força de trabalho no interior de uma mesma empresa, enquanto a apropriação privada dos meios se intensifica mais.

A produção passa a ser social, mas a apropriação continua a ser privada. Os meios sociais de produção continuam a ser propriedade privada de um número reduzido de indivíduos. Mantém-se o quadro geral da livre concorrência formalmente reconhecida, mas o jugo de um punhado de monopolistas sobre o resto da população torna-se cem vezes mais duro, mais concreto, mais insuportável. (LÊNIN, 2007, p. 32)

Portanto, o imperialismo se caracteriza principalmente pela etapa monopolista do capitalismo, em que a concentração da produção atinge níveis extremamente elevados. Mas é preciso reconhecer, ainda, outros traços fundamentais que constituem essa nova fase histórica particular do capitalismo para que possamos ter uma visão total que do caracteriza o imperialismo.

A produção do conhecimento vem se concretizando em meio a essa conjuntura socioeconômica e se estabelece segundo os ditames do capital, pois as políticas de pós-graduação e de ciência e tecnologia estão intrinsecamente ligadas aos processos de acumulação e expansão do capital.

Considerando que um dos espaços de maior produção de conhecimento se encontra nos programas de pós-graduação, avançamos na explicação de como as políticas de pós-graduação implantadas nas instituições de Ensino Superior em nosso país se inserem nesta conjuntura

\footnotetext{
${ }^{8}$ Essas novas características definidoras do capitalismo advindo do século XX configuram uma nova fase histórica particular da produção social da existência nesse século, que Lênin (2007), em sua obra "O imperialismo, fase superior do capitalismo", denominou de imperialismo.
} 
socioeconômica, considerando uma breve análise dos PNPG que vêm historicamente sendo implantados.

\section{Políticas de Pós-Graduação: Planos Nacionais e seus objetivos}

Segundo Silva (1997, f. 30), os esforços no sentido de regulamentar a pósgraduação por parte do estado brasileiro, perpassou por condições do modelo econômico do período de governo militar, caracterizado por uma mudança de uma política econômica baseada na importação de mercadorias e na importação de capital estrangeiro. Entretanto, existia nas universidades focos de resistência à política econômica adotada pelo governo militar, que sofriam repressão. O governo militar nesse período imprimia medidas para conter o movimento estudantil e enquadrá-los no regime político adotado. Entre essas medidas, de acordo com Silva (1997, f. 30) a principal é proveniente dos acordos MEC-USAID que abrangiam todas as esferas da educação formal; no que tange à educação superior, esses acordos buscavam aplicar a ideologia do progresso empresarial que se baseia na prioridade das mudanças quantitativas, na valorização da ciência aplicada, da engenharia, das relações públicas e da perícia administrativa. Além disso, esses acordos tinham como meta reforçar a autoridade dos modelos tradicionais de educação, bem como buscavam assumir uma postura conformista e valorizar normas burocráticas nas instituições de ensino.

O interesse dos Estados Unidos na intervenção da regulamentação da educação no Brasil deve-se na verdade a interesses de ordem políticoeconômica, pautado no projeto de expansão do capital norte-americano e na construção de um modelo econômico de desenvolvimento dependente no Brasil. Tratava-se, portanto, de garantir, através desses acordos, a mão de obra necessária para instituir esse novo modelo econômico (SILVA, 1997, f. 32-33).

Todas essas medidas políticas que alimentaram a pós-graduação no Brasil e que foram determinadas pelo desenvolvimento econômico pautado no avanço da ofensiva imperialista norte-americana, trouxeram implicações epistemológicas na produção do conhecimento; muitas das quais, ainda se 
fazem presentes nos dias de hoje, reforçados por mecanismo provenientes dos PNPG.

É neste contexto que surge pela primeira vez em 1973, uma política específica para a área de pós-graduação sob a forma da I PNPG que vigorou no período de 1975 a 1979, tendo sido aprovado pelo governo Geisel e instituído pelo Conselho Nacional de Pós-graduação, grupo interministerial criado pelo decreto 73.441 no governo Médici (SILVA, 1973, f. 33).

O I PNPG traz como objetivos para a pós-graduação: 1) Formar professores para o magistério universitário, a fim de atender à expansão quantitativa deste ensino e à elevação da sua qualidade; 2) formar pesquisadores para o trabalho científico, a fim de possibilitar a formação de núcleos e centros, atendendo às necessidades setoriais e regionais da sociedade; 3) preparar profissionais de nível elevado, em função da demanda do mercado de trabalho nas instituições privadas e públicas (BRASIL, 2004 p. 125).

O I PNPG deu início ao processo de expansão da pós-graduação sob o controle do estado, que buscou a formação de um novo quadro de recursos humanos para o atendimento das necessidades postas pela realidade conjuntural do mercado de trabalho no modelo de expansão industrial dependente de capital estrangeiro norte-americano. As produções stricto sensu foram desenvolvidas em princípios epistemológicos que correspondiam ao modelo político-econômico de expansão do capital, ou seja, estudos reduzidos a interesses técnicos de maximização de resultados através de metodologias de quantificação desprovidas de qualquer esforço de crítica às relações sociais estabelecidas e proposições de transformação da realidade existente.

O II PNPG, instituído durante o governo de João Baptista de Oliveira Figueiredo e que vigorou no período de 1982 a 1985, caracterizou-se por um momento histórico de consolidação dos cursos já existentes. Partiu de pressupostos contidos em orientações do III Plano Nacional de Desenvolvimento (PND) e do III Plano Básico de Desenvolvimento Científico e Tecnológico (PBDCT), o II PNPG fundamenta-se em cinco principais premissas: 1) A existência de um número crescente de 
profissionais, pesquisadores e docentes altamente qualificados viabiliza um desenvolvimento científico, tecnológico e cultural próprio e representa garantia real para a afirmação dos valores genuinamente brasileiros; 2) a consolidação da pós-graduação depende de um sistema universitário e de institutos de pesquisa, estável e dinâmico em todos os seus níveis e setores, e o seu desenvolvimento pressupõe a existência de condições materiais e institucionais indispensáveis para a plena realização de suas finalidades; 3 ) a pós-graduação baseia-se na existência de docentes e pesquisadores efetivamente engajados na produção de novos conhecimentos científicos, tecnológicos ou culturais, em instituições que lhes garantam adequada dedicação horária, carga de ensino compatível com a pesquisa e as outras formas de produção intelectual. Além de condições de instalações e infraestrutura necessárias; 4) o desenvolvimento da pós-graduação depende igualmente da reformulação da estrutura e do funcionamento das instituições acadêmicas que carecem de uma maior dinamização e de uma desburocratização internas; 5) a existência de fontes múltiplas de financiamento, cuja atuação contribua para o êxito da Política Nacional de Pós-Graduação, é considerada um fator indispensável na complementação dos recursos orçamentários das instituições, no processo de implantação, desenvolvimento e maturação de um moderno complexo de pesquisa e pósgraduação (BRASIL, 2004, p. 178).

O referido plano salientou a necessária participação ativa de um número crescente de pesquisadores em todos os setores sociais, cabendo, portanto, a pós-graduação o papel central na formação e aperfeiçoamento dos mesmos. Para isso, estabeleceu três objetivos básicos, segundo os apontamentos de Barros (1998, p. 137): 1) aumentar qualitativamente o desempenho global do sistema, pela criação de estímulos e condições favoráveis, bem como acionando mecanismos de acompanhamento e avaliação; 2) compatibilizar pós-graduação e pesquisa com as prioridades nacionais e com a natureza das matérias de formação básica que a precedem na universidade; 3) buscar uma melhor coordenação entre as diversas instâncias governamentais que atuam na área de pós-graduação. 
De acordo com Silva (1997, p. 49), durante a vigência do II PNPG ocorreram muitas críticas referentes à estrutura dos cursos de mestrado e doutorado, quanto às tendências filosóficas a aos interesses políticos; se faziam denúncias ao engessamento que representavam as áreas de concentração e reivindicavam-se novas concepções de pós-graduação. Os indicadores dessas mudanças, porém, só começaram a se concretizar na vigência do III PNPG.

O III PNPG foi aprovado em 1986, durante o governo de José Sarney e vigorou no período de 1986 a 1989. O plano, logo em sua introdução, aponta que muitos estudos, por parte de órgãos do governo e da comunidade científica foram realizados no intuito de resolver problemas relacionados a política de formação de recursos humanos; entretanto, alerta para o fato de que o país ainda não possui um número suficiente de cientistas que possibilitasse atingir, a curto prazo, a plena capacitação científica e tecnológica, sendo, portanto, necessário um programa agressivo de formação de recursos humanos qualificados com o objetivo de atingir a independência econômica, científica e tecnológica do país no século XXI (BRASIL, 2004, p. 193).

Nesse sentido, o III PNPG traçou os seguintes objetivos: 1) consolidação e melhoria do desempenho dos cursos de pós-graduação; 2) institucionalização da pesquisa nas universidades, para assegurar o funcionamento da pós-graduação; 3) integração da pós-graduação no sistema de Ciência e Tecnologia, inclusive com o setor produtivo (BRASIL, 2004, p. 195).

Segundo Silva (1997, p. 57), embora apresentasse um caráter aparentemente crítico, mesmo o III PNPG reconhecendo inclusive os problemas gerados pela política inicial dos cursos de pós-graduação, não conseguiu atingir os objetivos propostos para superar os desafios emergentes; isto porque o governo assumiu uma postura de total desrespeito e descaso para com a pós-graduação, resultando em sucateamento e abandono da mesma; tanto o governo Sarney quanto o governo Collor, pautaram-se numa política de cortes orçamentários que reduziram 
drasticamente as verbas federais para o desenvolvimento da pesquisa, além de terem extinguido o Ministério da Ciência e Tecnologia.

No governo de Itamar Franco não houve mudanças significativas na política de pós-graduação e de ciência e tecnologia, mas teve um avanço com a volta do Ministério de Ciência e Tecnologia que resultou em ganhos imediatos como o aumento de verbas para a área, a criação de carreira de pesquisa para os órgãos federais, a correção nos valores das bolsas, a criação de novos programas e a retomada de outros que haviam sido interrompidos.

Nessas correlações de forças, muitos problemas ainda perduraram, culminando no baixo índice de publicações científicas dos professores ligados as universidades, no abandono da carreira acadêmica por pesquisadores, ainda jovens, devido aos obstáculos de ordem econômica, política e burocrática, na evasão de pesquisadores para outros países com melhores condições objetivas para o desenvolvimento da pesquisa científica e na baixa qualidade das pesquisas desenvolvidas no país.

Segundo Hostins (2006, p. 142) a década de 1990 foi marcada pela mudança ou redirecionamento das funções da universidade pública do status de identidade pública, própria do Estado de Bem Estar, para o status de identidade mercantil, própria do Estado Empresarial que trouxeram implicações expressas na expansão significativa da matrícula, a diversificação da oferta, as propostas de mestrados profisssionalizantes, diversificação das fontes de financiamento, as alianças estratégicas entre agências internacionais, governos e corporações, a diferenciação dos docentes em função de indicadores de produtividade, a internacionalização e globalização do conhecimento, o predomínio de Tecnologias da Informação e da Comunicação e de alternativas de aprendizagem à distância, a redefinição das estruturas que regulam a produção e circulação do conhecimento em âmbito global.

As políticas de ajuste pautadas no neoliberalismo atingiram seu auge durante os dois mandatos do governo de Fernando Henrique Cardoso e impulsionaram o processo de privatização e mercantilização da universidade sob o pretexto da melhoria e democratização da educação superior. Neste 
sentido, muitos documentos que orientaram a política de pós-graduação neste período suscitaram mudanças como a diminuição do tempo de certificação, a redução do número de bolsas e de seu tempo de duração, a redefinição do mestrado com o privilegiamento do doutorado, a vinculação de teses e dissertações a projetos de pesquisa institucional (HOSTINS, 2006, p. 13).

Houve neste período uma tentativa de um novo plano de pósgraduação, mas uma série de circunstâncias, como sucessivas crises na economia que geraram cortes no orçamento para aplicação do plano e o afastamento de agências de fomento do processo de elaboração do mesmo, impediram que este fosse concretizado. Mas, segundo Martins (apud HOSTINS, p. 154, 146), algumas das recomendações que faziam parte deste plano foram implantadas pela diretoria da CAPES, onde se destaca a expansão do sistema nacional de pós-graduação, a diversificação do modelo vigente de pós-graduação de modo a atender também ao meio profissional, as mudanças no processo de avaliação, a implantação do portal de periódicos e inserção internacional da pós-graduação.

Em 2004, durante o governo Lula, foi construído o IV PNPG que vigorou no período de 2005 a 2010; esse plano afirma que um dos seus objetivos fundamentais é a expansão do sistema de pós-graduação, visando o aumento do número de pós-graduandos necessários para a qualificação do sistema de ensino superior do país, do sistema de ciência e tecnologia e do setor empresarial (BRASIL, 2004, p. 9).

O IV PNPG retoma os pontos essenciais de todos os planos anteriores, a importância e os limites de cada e basicamente reafirma objetivos e diretrizes para o desenvolvimento do sistema nacional de pós-graduação já desenvolvidos nos planos anteriores. Neste sentido, aponta como aspectos fundamentais para sua formulação os fatores: 1) evolução das formas de organização da pós-graduação brasileira; 2) formação de recursos humanos, pesquisa, desenvolvimento e o mercado de trabalho; 3) integração entre pósgraduação e graduação; 4) carreira acadêmica e qualificação do corpo docente do sistema de ensino superior; 5) avaliando a avaliação da CAPES: problemas e alternativas; 6) expansão da pós-graduação: crescimento das 
áreas e desequilíbrio regional; 7) financiamento e custo da pós-graduação (BRASIL, 2004, p. 17).

Portanto, o IV PNPG apresenta uma grande preocupação com a avaliação do sistema, que deve tomar como medida de qualidade da pósgraduação, a qualidade da produção científica e tecnológica dos grupos de pesquisa que a compõem, assim como o número de doutores titulados que saíram da Iniciação Científica diretamente para o doutorado e a interação da pós-graduação com o setor empresarial.

Hoje, nos encontramos no período de vigência do V PNPG (20112020), que está assentado em um país que se tornou nos últimos anos um dos maiores receptores de capitais estrangeiros, ou seja, trata-se de uma mudança que colocou o país definitivamente na lógica do capital mundializado. Como elemento que comprova essa afirmativa, destacamos que de 2009 para 2010 o Brasil passou da $15^{\text {a }}$ para a $5^{\text {a }}$ posição entre os principais destinos de investimentos estrangeiros diretos (SILVA JUNIOR; FERREIRA; KATO, 2013, p. 437).

$\mathrm{O}$ aumento destes investimentos deve-se as contradições da própria lógica do novo quadro econômico mundial de predominância financeira que provocou mais impacto nos países em desenvolvimento da periferia do sistema econômica capitalista, como o Brasil. Essas mudanças na conjuntura econômica pressupõem, por sua vez, uma contínua reforma do aparelho do estado, produzindo a matriz política, teórica e ideológica para a reforma das demais instituições republicanas e entre elas as universidades, fato que no Brasil já vem ocorrendo desde 1995, orientada pelo Plano Diretor de Reforma do Aparelho de Estado. Trata-se de um período, portanto, em que se dão profundas mudanças nas universidades que são postas a serviço da valorização do capital.

Situado nesta conjuntura, o V PNPG apresenta três pontos essências para compreendermos as perspectivas da pós-graduação nesta década, considerando suas relações com a conjuntura econômica apresentada acima.

O primeiro se refere ao forte apelo educacional na forma de políticas públicas direcionadas para todos os níveis de ensino, onde se destacam a preocupação com a formação técnica para alunos de baixa renda do ensino 
médio, através do Programa Nacional de Acesso ao Ensino Técnico e Emprego (PRONATEC), a democratização do acesso ao ensino superior, através do Programa Universidade Para Todos (PROUNI), modalidade de educação à distância e expansão de universidades públicas e privadas, e por fim, a expansão da pós-graduação através de programas como o "Ciência sem Fronteiras" e do incremento nas verbas da CAPES e do CNPq ao fomento de bolsas e de pesquisas, através de editais de apoio que privilegiam áreas tecnológicas e pesquisas fortemente vinculadas à Política Industrial Tecnológica e de Comércio Exterior (PITCE) (SILVA JÚNIOR; FERREIRA; KATO, 2013, p. 451).

O segundo ponto se refere ao sistema de avaliação, classificação e orientação da pós-graduação que colocam uma camisa de força a autonomia universitária, comprometendo fortemente a formação de professores e a produção do conhecimento que é fortemente afetada pelo modelo perverso de avaliação da CAPES pautada em indicadores de excelência que burocratiza o processo de produção do conhecimento na universidade e restringe a crítica e o debate livre (JÚNIOR; FERREIRA; KATO, 2013, p. 451).

Mediante o exposto, reconhecemos que no atual processo histórico real a universidade se transformou em instrumento para o processo de produção e valorização do capital que atende aos interesses de uma classe minoritária. A breve análise dos PNPG que realizamos, confirma essa tese. Os planos são apenas uma expressão no plano político do domínio material exercido pela classe burguesa.

Considerando a problematização levantada na pesquisa, avançamos em expor, a partir da análise epistemológica em que bases se colocam as produções, considerando as políticas implementadas pelos PNPG.

Dados de análise epistemológica da produção stricto sensu dos professores de Educação Física que trabalharam em cursos de formação, de 1982 a 2012, no estado da Bahia

O procedimento de investigação epistemológica nos permitiu reconhecer as bases que alimentaram o pensamento dos pesquisadores para promover suas 
pesquisas, considerando nexos e relações com os PNPG, para expor os sistemas lógicos que geraram seus interesses e caminhos teóricometodológicos.

Para isso, tivemos que reconhecer o período em que as (142) produções foram identificadas e defendidas, e relacionar com o período de vigência de cada PNPG. Com esse procedimento identificamos elementos de análise explicativos sobre quais e quantas produções foram elaboradas, assim como reconhecer implicações políticas e científicas que sofreram as produções defendidas no período de vigência de cada PNPG.

Primeiramente relacionamos o período em que foram defendidas as $(142)^{9}$ produções identificadas com o período de vigência dos PNPG para termos uma noção do quantitativo dessas produções.

\begin{tabular}{|c|c|c|}
\hline PNPG & Período de vigência & Número de Produções defendidas \\
\hline I & 1975 a 1979 & 0 \\
\hline II & 1982 a 1985 & 1 \\
\hline III & 1986 a 1989 & 0 \\
\hline Sem PNPG & 1990 a 2004 & 49 \\
\hline IV & 2005 a 2010 & 86 \\
\hline V & 2011 a 2020 & 6 \\
\hline
\end{tabular}

Quadro 01 - Volume das (142) produções stricto sensu defendidas em relação aos períodos. de vigência dos PNPG.

Evidenciamos com esse quadro de realidade que durante a vigência do I PNPG não tivemos nenhuma produção defendida; a primeira que identificamos foi em 1982, já na vigência do II PNPG, sendo, aliás, a única deste período. Na vigência do III PNPG novamente nenhuma produção foi identificada. Trata-se de um período em que a pós-graduação passava por um processo de expansão dos cursos de mestrado e doutorado e também foi um período de expansão das universidades públicas e, principalmente, das privadas com cursos de Educação Física, fenômeno este que ocorreu mais rapidamente nas regiões sul e sudeste por determinações políticas de interesses econômicos de desenvolvimento do país.

Além disso, como já apontamos, anteriormente, o período de vigência do III PNPG é marcado por um processo de profundo abandono e descaso

\footnotetext{
${ }^{9}$ Dados extraídos das produções stricto sensu de professores de Educação Física que trabalham nos cursos de formação de professores de Educação Física no estado da Bahia e que foram identificadas.
} 
da educação em geral por parte do estado, com cortes orçamentários que promoveram um impacto muito negativo para pós-graduação como redução de bolsas, redução do investimento em programas que deixaram de funcionar, e, como principal impacto, o desmantelamento do Ministério da Ciência e Tecnológica.

Dessa forma, o novo quadro, ainda reduzido de professores (mestres e doutores) deste período de expansão da pós-graduação é aproveitado em maior número pelas universidades da região sul e sudeste. Por isso, identificamos apenas uma produção defendida no período de vigência dos três primeiros PNPG que vão de 1975 a 1989, ou seja, os professores que obtém seus títulos neste período, além de estarem em menor número em relação a partir do final dos anos de 1990, não se deslocam para o estado da Bahia, pois encontram muito mais possibilidade de inserção no mercado de trabalho docente nas universidades da região sul e sudeste; esse dado é também destacado quando apontamos no quadro 02, abaixo, que a maioria dos cursos de Educação Física das IES do estado da Bahia foi implantada a partir do final dos anos de 1990.

A partir dos anos de 1990 tem início um período de maior produtividade no âmbito da pós-graduação no Brasil. Das (67) produções que realizamos análise epistemológica, identificamos (49) defendidas até o ano de 2004. Além disso, houve uma expansão muito grande de universidades públicas e principalmente privadas com cursos de Educação Física no estado da Bahia, principalmente no final dos anos 90 e início dos anos 2000, conforme observamos no quadro abaixo.

\begin{tabular}{|l|l|}
\hline \multicolumn{1}{|c|}{$\begin{array}{c}\text { IES com cursos de Educação } \\
\text { Física/Bahia }\end{array}$} & \multicolumn{1}{c|}{ Data de início dos cursos } \\
\hline UFBA & $03 / 06 / 1988$ \\
\hline UFRB & $15 / 03 / 2010$ \\
\hline UNEB (Campos Alagoinhas) & $19 / 04 / 2006$ \\
\hline UNEB (Campos Guanambi) & $04 / 06 / 2004$ \\
\hline UNEB (Campos Jacobina) & $19 / 04 / 2006$ \\
\hline UESB & $01 / 03 / 1997$ \\
\hline UESC & $28 / 08 / 2009$ \\
\hline UEFS & $03 / 03 / 1997$ \\
\hline UNIME & $05 / 08 / 2002$ (Licenc.); $02 / 01 / 2009$ (Bacharel.) \\
\hline FTC (Campos Salvador) & $09 / 09 / 2002$ \\
\hline FTC (Campos Itabuna) & $01 / 01 / 2003$ \\
\hline FTC (Campos Vitória da & $14 / 02 / 2005$ \\
\hline
\end{tabular}




\begin{tabular}{|l|l|}
\hline Conquista) & \\
\hline UNIRB (Campos Salvador) & $15 \backslash 07 \backslash 2005$ \\
\hline UNIRB (Campos Alagoinhas) & $12 \backslash 02 \backslash 2007$ \\
\hline UNIJORGE & $14 \backslash 02 \backslash 2005$ (licenc.); 3\02\2009 (Bacharel.) \\
\hline UCSAL & $1 \backslash 03 \backslash 1973$ \\
\hline FSBA & $18 \backslash 02 \backslash 2002$ (licenciatura); 18\11\2009 (Bacharel.) \\
\hline AGES & $14 \backslash 02 \backslash 2008$ \\
\hline FAM & $1 \backslash 09 \backslash 1989$ \\
\hline FAN & $1 \backslash 01 \backslash 2004$ \\
\hline FAMAM & $20 \backslash 03 \backslash 2006$ \\
\hline
\end{tabular}

Essa realidade aponta, portanto, para um maior número de professores (mestres e doutores) formados entre 1990 e 2004, visto a maior demanda de professores com títulos de mestre e doutor devido à expansão das universidades com cursos de Educação Física, tanto de licenciatura como de bacharelado.

A expansão quantitativa, no entanto, não é seguida da expansão qualitativa dos novos cursos de pós-graduação e dos novos cursos de Educação Física do estado da Bahia. O modelo hegemônico de pósgraduação que passou a vigorar neste período é o do empreendedorismo, cuja função principal é o da formação técnica unilateral.

O principal fator que reconhecemos e que explica este processo de crescimento muito elevado de novos cursos de Educação Física e, consequentemente da existência de um maior número de professores de Educação Física trabalhando no estado da Bahia, são as mudanças no movimento da economia política do Brasil que a partir dos dois mandatos presidenciais de Fernando Henrique Cardoso, pautadas no neoliberalismo, culminaram no processo de privatização massiva das universidades e no enfraquecimento da universidade pública; essa realidade perdurou nos dois governos posteriores. Por isso, esse processo continua se fortalecendo, o que nos permite identificar a existência de 86 produções no período de vigência do IV PNPG que vai de 2005 a 2010. Considerando as (67) produções stricto sensu levantadas que realizamos a análise epistemológica, identificamos que a produção da maior parte delas está concentrada entre os anos de 2005 a 2010. 
Relacionando os anos em que essas produções foram defendidas com os períodos de vigência dos PNPG, temos o seguinte quadro:

\begin{tabular}{|l|c|c|}
\hline PNPG & Período de vigência & Número de Produções defendidas \\
\hline I & 1975 a 1979 & \\
\hline II & 1982 a 1985 & - \\
\hline III & 1986 a 1989 & - \\
\hline Sem PNPG & 1990 a 2004 & 14 \\
\hline IV & 2005 a 2010 & 52 \\
\hline V & 2011 a 2020 & 01 \\
\hline
\end{tabular}

Quadro 03 - Volume e identificação das (67) produções stricto sensu levantadas defendidas em relação aos períodos de vigência dos PNPG.

Foram, portanto, (14) produções defendidas entre o ano de 1990 a 2004, período em que não houve um PNPG oficial orientando a pósgraduação e (52) produções defendidas entre os anos de 2005 a 2010, período de vigência do IV PNPG.

Através da análise epistemológica dessas (67) produções, considerando as teorias utilizadas ou elaboradas e as concepções de homem/sociedade que foram desenvolvidas na investigação de seus objetos, identificamos os ancoradouros conceituais ${ }^{10}$ que estas produções desenvolvem para responder aos problemas que levantaram. A partir desses ancoradouros, construímos dois quadros, agrupando todos os ancoradouros correspondentes à lógica formal e dialética para reconhecer, através da análise epistemológica, o que apontam essas produções.

\section{Produções da lógica formal e dialética: O que apontam as produções stricto sensu e os nexos com os PNPG}

$\mathrm{Na}$ análise das produções, os elementos que encontramos a partir da leitura dos textos e na identificação dos ancoradouros conceituais de análise foram essenciais e nos permitiram situar cada pesquisa em uma dada lógica.

No que diz respeito às teorias utilizadas ou elaboradas, encontramos em algumas pesquisas o trato de teorias que levam em consideração conceitos advindos das ciências biológicas para a interpretação dos dados

\footnotetext{
${ }^{10}$ Denominamos de ANCORADOUROS CONCEITUAIS, as categorias de análise, que são localizadas na totalidade das produções, considerando uma extração da análise do substrato material objetivo da realidade dos campos específicos de cada monografia. Esse termo foi extraído da produção de Hostins ( 2013, p. 418).
} 
levantados; essas pesquisas lançam mão de teorias preocupadas com a questão da mensuração ou avaliação de energias gastas na atividade física e desenvolvimento de capacidades físicas e biológicas de praticantes de atividades ou exercícios físicos.

Também, utilizam teorias voltadas para a interpretação dos resultados a partir do estabelecimento de relações entre variáveis quantitativas e qualitativas, modelos de fadiga, comparação de variáveis de fatores de risco cardiovascular que implicam no reconhecimento de uma relação linear e muito estreita entre a prática de atividade ou exercício físico e a obtenção de qualidade de vida, ou ainda, entre, a não prática de atividade ou exercício físico e o surgimento de doenças ou desequilíbrio da homeostase.

Outras pesquisas se pautam em teorias baseadas em leis e propriedades da física para analisar o movimento humano; são teorias que trabalham com conceitos provenientes de estudos sobre a capacidade do homem de se movimentar durante a atividade física, visando o melhor desempenho possível; a preocupação dessas teorias é com a análise da evolução do movimento através da biomecânica e com o sistema proprioceptivo na manutenção da aptidão física. Essas pesquisas também reiteram a relação linear e muito reduzida entre a prática da atividade ou exercício físico com a obtenção de saúde física e mental.

Outro elemento importante que podemos apontar dessas teorias é o caráter acrítico com relação à realidade objetiva dos fenômenos estudados; as teorias não dão explicações do objeto a partir de um determinado contexto real. É possível identificar no quadro dos ancoradouros conceituais de análise teorias que explicam o movimento humano, por exemplo, sob o aspecto puramente formal, de forma que não é possível identificar a essência do movimento humano no contexto de uma dada realidade; uma teoria que explica o movimento humano na área da Educação Física como qualquer atividade que gera gasto energético além dos níveis de repouso; por exemplo, não define a essência do movimento para a produção da existência humana, pois é possível atribuir o mesmo conceito a qualquer outro animal.

Ainda, considerando as pesquisas situadas na lógica formal, 
encontramos a utilização de teorias que, ao contrário dessas primeiras que identificamos, dão um enfoque maior ao aspecto subjetivo, isto é, põem o sujeito com seus valores, sentimentos e sua cultura em destaque, em detrimento de elementos da realidade objetiva.

Nessas teorias, identificamos conceitos relacionados à determinadas significações produzidas sobre a realidade, de bem estar subjetivo; conceitos relacionados a formação integral do ser humano, a inclusão social, a representações sociais, a cultura como fator da simbologia humana. Essas teorias tomam basicamente como categorias de análise a subjetividade e a cultura humana. São, portanto, teorias que investigam o objeto com base numa lógica mais abrangente, pois no processo do pensamento tenta captar a realidade do fenômeno situado em um contexto determinado.

Como essas teorias, implicitamente, negam a inter-relação dialética de base do modo de produção que alimentam a infraestrutura, admitem mudanças apenas no que diz respeito à superestrutura social ou a mudança no âmbito da subjetividade; trata-se, portanto, da defesa de mudanças formais e não estruturais. Por isso essas teorias não partem da própria realidade concreta, mas daquilo que se pensa dela; o que se deve mudar é o que se pensa da realidade e não a própria realidade.

Em geral, as teorias utilizadas ou elaboradas por essas pesquisas não consideram a articulação do lógico com o histórico; o aspecto histórico dos fenômenos estudados é deixado de lado em detrimento de sua fixidez e cristalização; não compreendem o movimento do objeto a partir de suas contradições internas, mas como algo dado a priori.

As produções situadas na lógica dialética tomam, em sua grande maioria, como base teórica, categorias fundamentais que constituem o materialismo histórico e dialético, como modo de produção, trabalho no processo de transformação do homem e da sociedade, emancipação humana e transformação social e produzem a articulação do lógico com o histórico.

O modo de produção é uma categorial fundamental que aparece nas teorias utilizadas ou elaboradas pelas produções situadas na lógica dialética; a partir desta categoria essas produções partem do pressuposto de que não é possível compreender a realidade do fenômeno estudado sem estabelecer os 
nexos e as relações com o modo de produção que se caracteriza como aquilo que determina em ultima estância o objeto estudado pelo pesquisador. Portanto, a categoria modo de produção é um elemento central que faz parte do dispositivo lógico de apreensão da realidade nestas pesquisas, sem a qual não é possível atingir a essência do fenômeno estudado. Outro aspecto importante destas teorias desenvolvidas pelos professores de Educação Física é a apropriação da categoria trabalho enquanto atividade vital do ser humano por meio da qual este constrói o mundo material dos homens e a si mesmo; essas teorias tomam a categoria trabalho para poder explicar como nos tornamos humanos e como os homens se relacionam com a natureza, isto é, com o objeto de sua atividade e como se relaciona com os outros homens.

O interesse na investigação dos fenômenos da realidade que apontam essas teorias é o de transformação da realidade concreta e de emancipação humana; o conhecimento produzido sobre o objeto investigado possui o intuito de alterar as condições objetivas que estão postas pela realidade do modo de produção capitalista que oprime e aliena o homem através da exploração do trabalho; portanto, são teorias que lançam mão da crítica, contextualizando e historicizando o objeto de investigação. Outra questão importante que podemos apontar destas teorias é a compreensão do conhecimento como resultado da articulação do lógico com o histórico; para essas teorias, o lógico caracteriza o reflexo do histórico, ou seja, as leis e formas do pensamento devem ser as leis e formas da realidade objetiva, que são, simultaneamente, meios para o pensamento captar a essência do objeto e o resultado do processo de investigação.

No que diz respeito à concepção de homem ou sociedade, as primeiras pesquisas que desenvolvem a lógica formal e cujas teorias possuem um enfoque mais biológico e mecânico, defendem uma concepção de homem que se caracteriza essencialmente pelo conjunto de suas características físicas e biológicas; essas pesquisas definem o homem como ser apartado de suas condições históricas, pois quando se referem ao homem não reconhecem as determinações sócio-históricas, não reconhecem um ser concreto, mas um ser abstrato, apartado da realidade da qual vive. Outra 
característica que podemos apontar desta concepção é que o homem não é entendido como sujeito ativo, transformador, mas é tomado apenas como objeto, como ser passivo, cujas únicas mudanças que sofre provem de adaptações advindas de circunstâncias do meio ambiente, ou seja, o homem não transforma o mundo, mas a ele deve se conformar, se adaptar.

Quanto à concepção de sociedade, não encontramos nenhuma dessas pesquisas preocupadas com sua definição; parece ser uma questão de menor importância para estes pesquisadores situar suas investigações em uma determinada formação social, o que demonstra o caráter acrítico destas pesquisas; podemos apontar que estas pesquisas, mesmo que de forma implícita, se colocam na defesa de um projeto histórico que preserva as relações de produção existente - capitalista. Já o segundo grupo de pesquisa que identificamos, que dão mais ênfase ao sujeito em suas teorias, defendem uma concepção de homem com individuo determinada pelas relações culturais, onde o homem não é considerado como um indivíduo passivo, mas como um ser ativo que cria o mundo através da sua subjetividade; a categoria cultura é amplamente apropriada nestas pesquisas no intuito de explicar o homem e a sociedade como produto de relações culturais e simbólicas. Mas a própria cultura não é pensada como um processo histórico que se dá na relação homem-natureza no processo de produção da existência, mas como categoria estanque, fruto da subjetividade a priori.

As produções que desenvolvem a lógica dialética tem como concepção de homem o ser humano entendido como resultado das relações materiais que estabelece com a natureza e com outros homens no processo de transformação da realidade para a produção da sua existência; para compreender a essência do ser humano, essas pesquisas se apoiam na categoria trabalho entendida como atividade vital humana. Trata-se, portanto, nessas pesquisas, de conceber o homem como ser concreto e histórico a partir das suas relações concretas e históricas na realidade objetiva, como ser que é produto e produtor da realidade na qual vive, como ser multideterminado e sócio-histórico, que possui a capacidade de se apropriar da cultura criada pelas gerações precedentes.

Quanto à concepção de sociedade, as produções desenvolvidas a partir 
da lógica dialética caracterizam a sociedade como produto histórico das contradições entre as relações de produção e as forças produtivas; partem do pressuposto de que a sociedade está dividida em classes com interesses antagônicos e que estão em luta pelo domínio político e econômico. Ao conceber a sociedade desta forma, essas produções apontam para a possibilidade de superação da sociedade dividida em classes por uma sociedade sem classes, ou seja, apontam para um projeto histórico que venha a superar o modo de produção capitalista.

O que vem sendo produzido nas produções stricto sensu em Educação Física, esporte e lazer não está separado das determinações da política de pós-graduação expressas nos PNPG. Todos os cinco planos que identificamos contém orientações que influenciam decisivamente na estrutura e modelo da pós-graduação no país. E o que pudemos reconhecer foi à determinação por parte do estado de uma política de fortalecimento do produtivismo que alimenta determinada lógica que formaliza interesses do capital.

Os PNPG reiteram enfaticamente, nos objetivos e nas diretrizes, a necessidade da formação de recursos humanos tendo em vista a elevação do padrão científico e cultural do país para a consecução da autonomia tecnológica e econômica. Entretanto, para a realização de tais objetivos, o que se vê nas medidas adotadas pelos principais órgãos responsáveis pela execução dos planos, como a CAPES e o CNPQ, são determinações que visam à retirada da autonomia das universidades, o estímulo à produção stricto sensu aligeirada. Há também interesses em promover critérios que estabelecem a diferenciação dos docentes através de indicadores de produtividade, há um visível rebaixamento da formação pós-graduada com a criação cursos precários de mestrado profissionalizante.

Tudo isso determina profundamente a estrutura da produção do conhecimento científico no âmbito dos programas de pós-graduação no Brasil. A realidade analisada aponta um ambiente bastante restrito para a produção do conhecimento no campo da Educação Física, que acaba por se conformar, em certa medida, a lógica que prevalece nos PNPG que foram analisados. 


\section{Considerações finais}

$\mathrm{Na}$ análise dos principais elementos que constituem os cinco PNPG, identificamos que os objetivos e diretrizes vêm apontando para a necessidade do governo promover maiores investimentos, mas em contradição existe uma política de defesa de um modelo de pós-graduação empreendedorista, que, calcada em princípios do modo de produção capitalista, se coloca em interesses da competitividade exacerbada entre os pesquisadores, produtivismo acadêmico, hierarquização no interior da universidade, determinações essas promovendo os alicerces da privatização da produção do conhecimento sistematizado e historicamente elaborado pela humanidade.

Todos esses fatores que refletem indicadores, portanto, de que a universidade está muito mais a serviço dos interesses da acumulação e reprodução do capital do que dos interesses da classe trabalhadora, constituem condições precárias e implicam sérios limites para o avanço da produção do conhecimento que é produzido nos programas de pósgraduação das universidades brasileiras.

Tomando como foco de análise das produções, seus fundamentos lógicos a partir de dois campos de análise (teorias utilizadas e elaboradas e concepção de homem/sociedade) sistematizados em uma matriz epistemológica e tendo como base de referência teórica, estudos pautados do materialismo histórico dialético, reconhecemos que as produções analisadas, de um modo geral, encerram limites lógicos que se configuram como entraves para o avanço dessa produção do conhecimento no sentido da possibilidade de construção de uma consistente base teórica que venha a responder de maneira concreta os reais problemas que a área vem impondo historicamente.

Esses limites lógicos se referem às teorias utilizadas ou elaboradas que não correspondem à prática social, pois não considera a dinâmica das relações de base da produção, o que acaba culminando em respostas idealistas e pragmáticas aos problemas que levantam para a investigação e também à forma como compreendem o homem/sociedade. A lógica que 
serve de base para o desenvolvimento destas pesquisas na área de Educação Física, esporte e lazer é a lógica formal, pois os elementos que identificamos nas teorias utilizadas ou elaboradas e concepções de homem/sociedade nestas pesquisas coincidem com os princípios da lógica formal que implicam na investigação dos fenômenos de forma fragmentada, estática e sem contradições.

É preciso, considerar, todavia, que o movimento da produção do conhecimento em Educação Física, esporte e lazer que investigamos, evidencia um crescimento no desenvolvimento de uma lógica explicativa da realidade dialética; mas trata-se, como podemos evidenciar, de pesquisas que andam na contramão das tendências políticas para a produção do conhecimento científico; a identificação de elementos lógicos que coincidem com os princípios da lógica dialética em quantidade relativamente significativa pode ser explicada pelo agravamento das próprias contradições do modo de produção capitalista, que demonstram pela prática social a debilidade e insuficiência do sistema lógico-formal para explicar essas mesmas contradições.

\section{Referências}

BRASIL. Ministério da Educação e Cultura. Coordenação de Aperfeiçoamento de Pessoal de Nível Superior. Plano de Pós-graduação - PNPG 2005-2010.

Brasília: CAPES, 2004. 2012 p.

BRASIL. Brasil. Ministério da Educação. Coordenação de Aperfeiçoamento de Pessoal de Nível Superior. Plano Nacional de Pós-Graduação - PNPG 2011-2020. Vol. 1. Brasília: CAPES, 2010. 309 p.

BARROS, Elionora Maria Cavalcanti. Política de pós-graduação na ótica do PNPGs. In: BARROS, Elionora Maria Cavalcanti. Política de pós-graduação no Brasil (1975/1990): um estudo da participação da comunidade científica. São Paulo, Ed. UFScar, 1998. Capítulo IV, p. 115-160.

ENGELS, Friedrich Do socialismo utópico ao socialismo científico. São Paulo: Global Editora. s/d. 79 p.aulo, Ed. UFScar, 1998. Capítulo IV, p. 115-160.

FRIGOTTO, Gaudêncio. A produtividade da escola improdutiva. 2a. ed. São Paulo: Cortez, 1984. 235 p.

HOSTINS, Regina Célia Linhares. Os Planos Nacionais de Pós-graduação (PNPG) e suas repercussões na Pós-graduação brasileira. Revista Perspectiva, Florianópolis, v. 
24, n. 1, p. 133-160, jan/jun. 2006. Disponível em:

http://www.perspectiva.ufsc.br. Acesso em: 24/07/2013

KOSIK, Karel. Dialética do concreto. São Paulo: Paz e Terra, 1995. 248 p.

LÊNIN, Vladimir Il'ich. O Imperialismo, fase superior do capitalismo. Brasília: Nova Palavra, 2007. 200 p.

MARX, Karl. O capital: crítica da economia política. Livro I. 20ª ed. Rio de Janeiro: Civilização Brasileira, 2002. 571 p.

MARX, Karl; ENGELS, Friedrich. A ideologia alemã. 3 ed. São Paulo: Martin Claret, 2005. 149 p.

MARX, Karl; ENGELS, Friedrich. Obras Escolbidas. V. 3. São Paulo: Editora Alfa Omega, 1980. 381 p.

MARX, Karl; ENGELS, Friedrich. Manifesto do partido comunista. São Paulo: Expressão Popular, 2008. $72 \mathrm{p}$.

SILVA JÚNIOR, João dos Reis; FERREIRA, Luciana Rodrigues; KATO, Fabíola Bouth Grello. Trabalho do professor pesquisador diante da expansão da pósgraduação no Brasil pós-LDB. Revista Brasileira de Educação, Rio de Janeiro, v. 18, n. 53, p. 435-456, jun. 2013.

SILVA, Rossana Valéria Souza e. Pesquisa em Educaşão Física: Determinações históricas e implicações epistemológicas. 1997. 278 f. Tese (Doutorado em Educação). Faculdade de Educação, UNICAMP, Campinas. 1997.

TAFFAREL, Celi Nelza Zulke. Do trabalho geral ao trabalbo pedagógico: contribuição ao debate sobre o trabalho pedagógico na Educação Física. Revista Motrivivência, Florianópolis, v. 22, n. 35, p. 18-40, dez. 2010. 